\title{
Purification and properties of acetyl-CoA:L-glutamate $\mathrm{N}$-acetyltransferase from human liver
}

\author{
Claude BACHMANN, Stefan KRÄHENBÜHL and Jean-Pierre COLOMBO \\ Department of Clinical Chemistry, Inselspital, University of Berne, Berne, Switzerland
}

\section{(Received 7 December 1981/Accepted 31 March 1982)}

Acetyl-CoA:L-glutamate $\mathrm{N}$-acetyltransferase (amino acid acetyltransferase, EC 2.3.1.1) was isolated from human liver mitochondria by precipitation with $\left(\mathrm{NH}_{4}\right)_{2} \mathrm{SO}_{4}$ and chromatography on hydroxyapatite, DEAE-cellulose and Sephacryl 300. This gave a 360-fold purification. The molecular weight was estimated to be approx. 190000 . The kinetic properties in the absence of arginine are compatible with a rapid-equilibrium random $\mathrm{Bi} \mathrm{Bi}$ mechanism. The estimated constants are: for the substrates $K_{\mathrm{m} \text {, acetyl-coA }}$ $4.4 \mathrm{mM}, K_{\mathrm{i} \text {, acetyl-CoA }} 4.7 \mathrm{mM}, K_{\mathrm{m}, \text { glutamate }} 8.1 \mathrm{mM}, K_{\mathrm{i} \text {, glutamate }} 8.8 \mathrm{mM}$; for the products, $K_{\mathrm{i} \text {, acetylglutamate }} 0.28 \mathrm{mM}, K_{\mathrm{i}, \mathrm{CoA}} 5.6 \mathrm{mM}$. The rate constant for the forward direction is $1.24 \mathrm{~s}^{-1}$. If in vivo the constants are of the same order of magnitude as in vitro, the synthesis of $\mathrm{N}$-acetylglutamate, an obligate activator of the first step of urea synthesis, can be expected to occur in the mitochondrion under conditions where the amino acid acetyltransferase is not saturated by its substrates. The regulation of the first step of urea synthesis could thus depend mainly on the intramitochondrial substrate and perhaps product concentrations of amino acid acetyltransferase.

The mitochondrial acetyl-CoA:L-glutamate $N$ acetyltransferase (amino acid acetyltransferase, EC 2.3.1.1) catalyses the formation of $N$-acetylglutamate and CoA from glutamate and acetyl-CoA. $\mathrm{N}$-Acetylglutamate is an obligate activator of the first enzyme of urea synthesis, the mitochondrial carbamoyl phosphate synthetase (EC 6.3.4.16). The amino acid acetyltransferase of rodent liver and duodenal mucosa has been purified and characterized by Shigesada \& Tatibana $(1971 a, b)$ and Ushiyama et al. (1981). They have also shown that it is activated by arginine, thus disclosing a positive feedback system for urea synthesis. Since the enzyme also plays a role in man, as exemplified by our discovery of a hyperammonaemic patient lacking amino acid acetyltransferase activity (Bachmann et al., 1981), we have purified the human enzyme and investigated some of its properties.

\section{Materials and methods}

\section{Materials}

L-[U- $\left.{ }^{14} \mathrm{C}\right]$ Glutamic acid was obtained from New England Nuclear Chemical (Dreieich, Germany), and impregnated silica-gel thin-layer sheets were from Gelman Instrument Co. (Ann Arbor, MI, U.S.A.). Otherwise all reagents were of analytical grade.

\section{Purification of amino acid acetyltransferase}

The enzyme was purified from a human liver obtained $4 \mathrm{~h}$ post mortem. The whole procedure was performed at $4{ }^{\circ} \mathrm{C}$. The liver was minced, washed with $0.9 \% \mathrm{NaCl}$ and homogenized in 4 vol. of $\mathrm{pH} 7.5$ buffer, containing mannitol $(0.21 \mathrm{M})$, sucrose (0.07 M), Tris ( $5 \mathrm{~mm})$ and EGTA (1 mM).

Mitochondria were prepared as described elsewhere (Hogeboom, 1955; Myers \& Slater, 1957). All of the following buffers contained dithioerythritol $(0.5 \mathrm{mM})$. The mitochondrial pellet was suspended in $200 \mathrm{ml}$ of potassium phosphate buffer $(\mathrm{pH} 7.5,50 \mathrm{~mm})$ and sonicated intermittently (total time $5 \mathrm{~min}, 40 \mathrm{~W}$ ) with efficient cooling. The disrupted mitochondria were centrifuged $(60 \mathrm{~min}$, $105000 \mathrm{~g})$ and $\left(\mathrm{NH}_{4}\right)_{2} \mathrm{SO}_{4}(243 \mathrm{~g} / \mathrm{l})$ was slowly added, with stirring, to the supernatant. After centrifugation for $30 \mathrm{~min}$ at $15000 \mathrm{~g}$, the precipitate was taken up in $20 \mathrm{ml}$ of the potassium phosphate buffer and centrifuged $(30 \mathrm{~min}, 105000 \mathrm{~g})$.

Chromatography on hydroxyapatite. The supernatant was applied to a hydroxyapatite column $(2.5 \mathrm{~cm} \times 25 \mathrm{~cm})$, previously equilibrated with potassium phosphate buffer (10 mM, pH 7.0), and eluted at $20 \mathrm{ml} / \mathrm{h}$ with potassium phosphate buffer, $\mathrm{pH} 7.0$, first with $150 \mathrm{ml}$ of $10 \mathrm{mM}$, then with $150 \mathrm{ml}$ of $70 \mathrm{~mm}$, and finally with $300 \mathrm{ml}$ of $250 \mathrm{~mm} ; 10 \mathrm{ml}$ fractions were collected. The fractions eluted 
between 420 and $460 \mathrm{ml}$ were pooled, dialysed against potassium phosphate buffer (10 mM, pH 7.5) and concentrated to $8 \mathrm{ml}$ with an Amicon filtration system.

$D E A E$-cellulose chromatography. The concentrate was applied on a DEAE-cellulose column $(1.6 \mathrm{~cm} \times 25 \mathrm{~cm})$ equilibrated with potassium phosphate buffer (10 mM, pH 7.5). A linear gradient (total volume $400 \mathrm{ml})$ of increasing phosphate $(\mathrm{pH} 7.5)$ concentration was applied, from $10 \mathrm{~mm}$ up to $250 \mathrm{~mm}$ (flow rate $20 \mathrm{ml} / \mathrm{h}$ ); 60 fractions each of $6 \mathrm{ml}$ were collected, and the fractions eluted between 60 and $96 \mathrm{ml}$ were pooled and dialysed against potassium phosphate buffer, $\mathrm{pH} 8.0(100 \mathrm{mM})$. They were concentrated as described above to $8 \mathrm{ml}$.

Gel-permeation chromatography. The concentrate was used for chromatography on a Sephacryl-300 column $(1.6 \mathrm{~cm} \times 75 \mathrm{~cm})$ equilibrated with potassium phosphate $(100 \mathrm{~mm}, \mathrm{pH} 8.0)$, and eluted at $15 \mathrm{ml} / \mathrm{h}$ with the equilibration buffer. The fractions $(4 \mathrm{ml}$ each) eluted from 76 to $92 \mathrm{ml}$ were dialysed against potassium phosphate $(100 \mathrm{~mm}$, pH 8.0) containing L-arginine ( $1 \mathrm{mM})$, and meanwhile the same column was equilibrated with this latter buffer. The non-diffusible material was concentrated to $8 \mathrm{ml}$ and the chromatography was repeated with the arginine-containing buffer. The fractions (each $4 \mathrm{ml}$ ) eluted between 68 and $92 \mathrm{ml}$ were dialysed against potassium phosphate buffer $(10 \mathrm{~mm}, \mathrm{pH} 8.0)$ without arginine and stored at $-20^{\circ} \mathrm{C}$ in small portions.

During chromatography, protein was monitored at $280 \mathrm{~nm}$ and the relevant fractions were analysed for protein by the method of Lowry et al. (1951). The polyacrylamide-gel electrophoresis was performed in Tris/glycine buffer containing dithioerythritol $(0.1 \mathrm{~mm})$ as described by Berüter et al. (1978).

\section{Molecular-weight determination}

The Sephacryl-300 column described above (total volume $150 \mathrm{ml}$, void volume determined with Blue Dextran $48 \mathrm{ml}$ ) was used, eluted with potassium phosphate buffer $(100 \mathrm{~mm}, \mathrm{pH} 8.0)$ at $15 \mathrm{ml} / \mathrm{h}$. Reference proteins ( $2 \mathrm{mg}$ of each) were aldolase $\left(M_{\mathrm{r}}\right.$ 158000), catalase $\left(M_{\mathrm{r}} 210000\right)$, ferritin $\left(M_{\mathrm{r}}\right.$ 440000) and thyroglobulin $\left(M_{\mathrm{r}} 669000\right)$. Calculations were done as described by Laurent \& Killander (1964).

\section{Assay methods}

The amino acid acetyltransferase activity was assayed at $37^{\circ} \mathrm{C}$ in Tris buffer (pH8.7, $\left.0.125 \mathrm{M}\right)$ containing $0.11 \%$ EDTA, acetyl-CoA and $\left[{ }^{14} \mathrm{C}\right]-$ glutamic acid purified beforehand on Dowex 50 (X8; $\mathrm{H}^{+}$form). Acetyl-CoA was used at $2 \mathrm{mM}$ and glutamate at $4 \mathrm{~mm}$ for assaying the activity during purification, and otherwise as indicated. The final incubation volume of $0.1 \mathrm{ml}$ contained approx. $1 \times 10^{6}$ d.p.m. of $\left[\mathrm{U}-{ }^{14} \mathrm{C}\right]$ glutamate.

Chromatography of the deproteinized incubation mixture with added carrier $N$-acetylglutamate was done on impregnated silica-gel thin-layer sheets with chloroform/methanol/formic acid $(160: 5: 2$, by vol.) and light petroleum (b.p. $40-60^{\circ} \mathrm{C}$ )/diethyl ether/formic acid $(50: 30: 2$, by vol.); the $N$-acetylglutamate spot revealed by Bromophenol Blue was cut out and its radioactivity determined. Details of the assay are given elsewhere (Colombo et al., 1982).

The kinetic data of the primary plots were computed by the method of Wilkinson (1961), and unweighted regression was used for the secondary plots and the calculation of the molecular weight.

\section{Results}

\section{Purification}

The purification resulting from each step is shown in Table 1 . The whole procedure leads to a 360 -fold purification with respect to the mitochondrial activity, with a recovery of $67 \%$.

\section{General properties of the purified enzyme}

The optimum pH (with $3.5 \mathrm{~mm}$-acetyl-CoA and $7 \mathrm{~mm}$-glutamate) with or without arginine $(1 \mathrm{mM})$ at $37^{\circ} \mathrm{C}$ was 8.5 , but was not critical between 8.25 and 8.75. The purified enzyme was stable over 2 months if kept frozen at $-20^{\circ} \mathrm{C}$.

The molecular weight calculated from the elution volume of the amino acid acetyltransferase $(81 \mathrm{ml})$ is approx. $190000[188000 \pm 11000$ (s.D.)]. The elution volumes of the reference proteins were: aldolase $83 \mathrm{ml}$, catalase $80 \mathrm{ml}$, ferritin $69 \mathrm{ml}$ and thyroglobulin $66 \mathrm{ml}$.

As judged from polyacrylamide-gel electrophoresis (Fig. 1), the final product still contains some minor impurities. Gels run in parallel were tested for enzyme activity. In the final product amino acid acetyltransferase activity was only found associated with the main protein band. On twodimensional t.l.c. only one product was detected, in a position identical with $\mathrm{N}$-acetylglutamate (by radioautography), when the final enzyme of the purification was used for the assay. In contrast, enzyme from the previous step still also gave a product co-chromatographing with malate $(2 \%$ of total product activity).

\section{Kinetic data}

The protocol used was as proposed by Rudolph \& Fromm (1979). We used in duplicate assays five concentrations of acetyl-CoA $(0.7,0.875,1.17$, $1.75,3.5 \mathrm{~mm}$ ) each with five concentrations of glutamate $(4.2,5.25,7.0,10.5,21 \mathrm{mM})$. 
Table 1. Purification of amino acid acetyltransferase from human liver

Details of each step are described in the text.

$\begin{array}{lcccc} & \begin{array}{c}\text { Volume } \\ (\mathrm{ml})\end{array} & \begin{array}{c}\text { Total activity } \\ (\mathrm{nmol} / \mathrm{min})\end{array} & \begin{array}{c}\text { Protein } \\ (\mathrm{mg})\end{array} & \begin{array}{c}\text { Specific activity } \\ \text { (nmol/min per } \\ \text { mg of protein) }\end{array} \\ \text { Disrupted mitochondria (supernatant) } & 78 & 11.9 & 1543 & 0.008 \\ \left.\text { (NH }_{4}\right)_{2} \mathrm{SO}_{4} \text { precipitate } & 22 & 23.2 & 458 & 0.051 \\ \text { Hydroxyapatite } & 8 & 16 & 105 & 0.153 \\ \text { DEAE-cellulose } & 8 & 9.5 & 27 & 0.349 \\ \text { Sephacryl without arginine } & 8 & 8.4 & 6.5 & 1.29 \\ \text { Sephacryl (arginine-containing buffer) } & 20 & 8.0 & 2.8 & 2.86\end{array}$

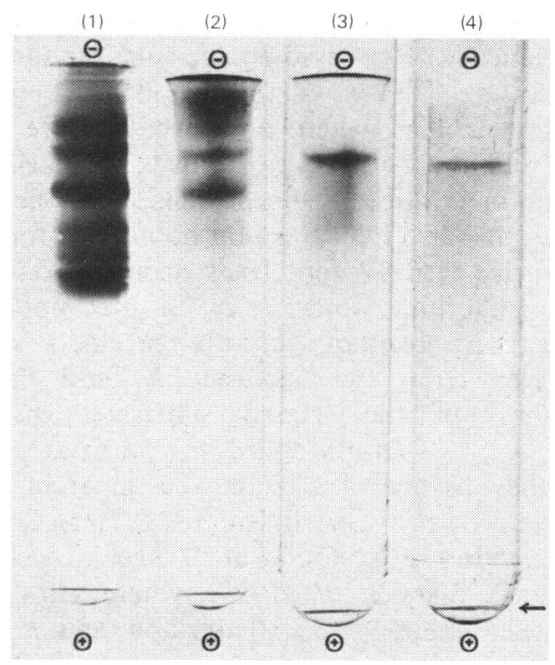

Fig.1. Polyacrylamide-gel electrophoresis of the product obtained (1) after hydroxyapatite column chromatography, (2) after DEAE-cellulose column, (3) after first

Sephacryl column, and (4) after final purification

For full details see the text. The arrow indicates the end of the gel.

Fig. 2 shows a Lineweaver-Burk plot of the data. Slopes and intercepts calculated as described by Wilkinson (1961) were used for secondary plots, from which Dalziel (1957) parameters were obtained. These are shown in Table 2 as well as derived kinetic constants. Assuming a molecular weight of 190000 , a rate constant of $1.24 \mathrm{~s}^{-1}$ is obtained for product formation under maximum rate conditions.

Since we were interested in the enzyme mechanism, product inhibition was also assayed by using various concentrations of the tested product and by varying one substrate while keeping the other constant at a non-saturating concentration. As shown in Figs. 3 and 4, competitive inhibition by

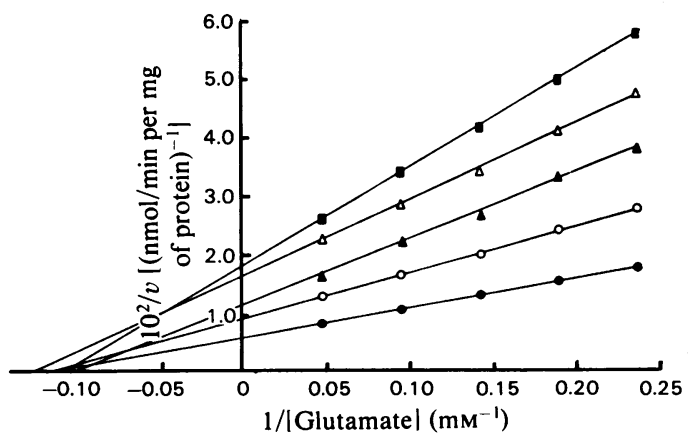

Fig. 2. Double-reciprocal plot of dependence on glutamate concentration of amino acid acetyltransferase activity at five concentrations of acetyl-CoA: $0,3.5 \mathrm{mM}$;

$0,1.75 \mathrm{mM} ; \triangle, 1.17 \mathrm{mM} ; \triangle, 0.875 \mathrm{mM} ; \square, 0.7 \mathrm{mM}$

The points are means of duplicate determinations.

$\mathrm{N}$-acetylglutamate (glutamate variable) and CoA (acetyl-CoA variable) was found. Replots of the slopes are linear and allow calculation of the apparent inhibition constants. These are $K_{\mathrm{i} \text {, acetylglutamate }} 0.49 \mathrm{mM}$ with acetyl-CoA at $3.5 \mathrm{mM}$, and $K_{\mathrm{i}, \mathrm{CoA}} 10.1 \mathrm{mM}$ with glutamate constant at $7 \mathrm{~mm}$.

The experiment shown in Fig. 2 was repeated in the presence of $0.36 \mathrm{mM}-\mathrm{N}$-acetylglutamate; the resulting Dalziel parameters were $\phi_{0} 2.45 \pm 0.12, \phi_{\mathrm{A}}$ $22.1 \pm 0.85, \phi_{\mathrm{B}} 11.5 \pm 0.12$ and $\phi_{\mathrm{AB}} 213.6 \pm 0.89$ (means \pm S.D., $n=5$; units as in Table 2). Only the $\phi_{\mathrm{AB}}$ term is affected.

Activation of amino acid acetyltransferase by L-arginine was tested at fixed concentrations of glutamate $(7 \mathrm{mM})$ and acetyl-CoA $(3.5 \mathrm{~mm})$ with increasing arginine concentrations up to $4 \mathrm{mM}$. We measured an increase from $75 \mathrm{nmol} / \mathrm{min}$ per $\mathrm{mg}$ of protein at zero arginine to $145 \mathrm{nmol} / \mathrm{min}$ per $\mathrm{mg}$ with arginine above $0.5 \mathrm{mM}$. The half-maximal activation was found at $30 \mu \mathrm{M}$-arginine. 
Table 2. Dalziel (1957) parameters and derived kinetic constants of human amino acid acetyltransferase Key: A, glutamate; B, acetyl-CoA. Mean values \pm S.D. are given $(n=5)$.

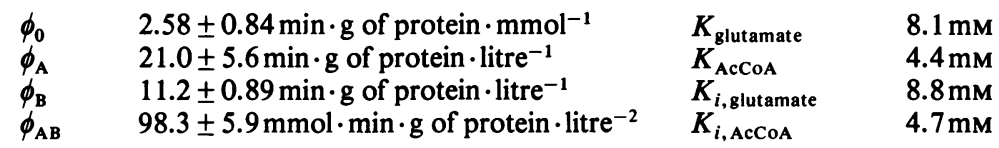

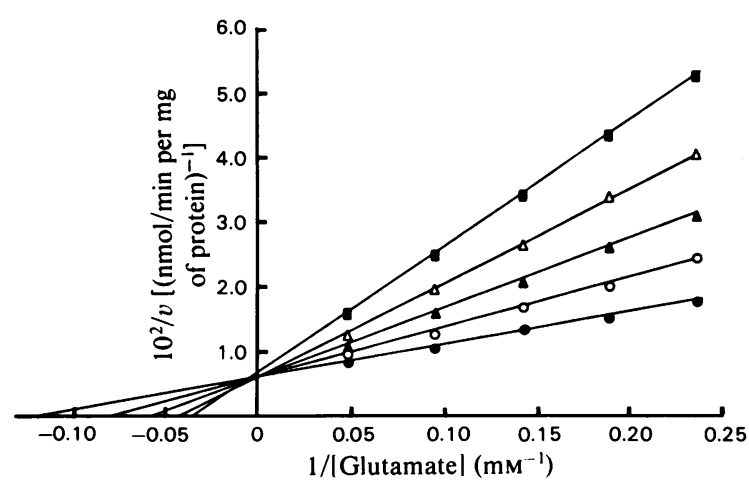

Fig. 3. Competitive product inhibition: double-reciprocal plot of dependence on glutamate concentration of amino acid acetyltransferase activity assayed in the presence of five concentrations of $N$-acetylglutamate: $\mathbf{\square}, 1.25 \mathrm{~mm} ; \Delta$, $0.83 \mathrm{mM} ; \Delta, 0.5 \mathrm{mM} ; 0,0.28 \mathrm{~mm} ; 0$, zero

Acetyl-CoA was constant at $3.5 \mathrm{~mm}$. The values shown are means of duplicate determinations.

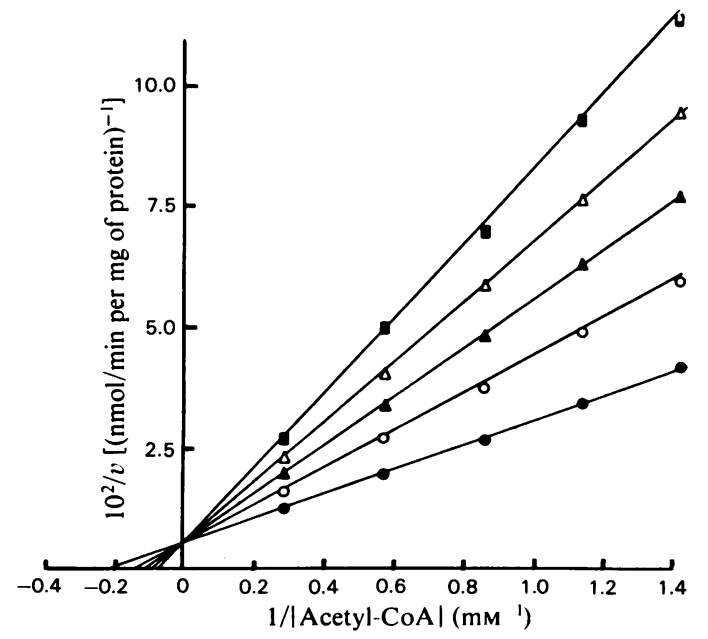

Fig. 4. Competitive product inhibition: double-reciprocal plot of amino acid acetyltransferase activity versus acetyl-CoA concentration measured at five CoA concentrations: $\square, 20 \mathrm{~mm} ; \triangle, 15 \mathrm{~mm} ; \triangle, 10 \mathrm{mM}$; , $5 \mathrm{~mm}$; none

Glutamate was constant at $7 \mathrm{~mm}$. The values shown are means of duplicate determinations.

\section{Discussion}

$N$-Acetylglutamate is an obligate activator of carbamoyl phosphate synthetase and plays a crucial role in the short-term regulation of urea synthesis in man (Bachmann et al., 1981). The kinetic data are in accordance with a rapid-equilibrium random $\mathrm{Bi} \mathrm{Bi}$ mechanism. This is supported by the productinhibition studies, where both products are competitive and only the $\phi_{\mathrm{AB}}$ term is affected when incubation is done in the presence of $\mathrm{N}$-acetylglutamate; this also indicates that no notable formation of abortive ternary complexes occurs. Assuming a rapid-equilibrium random $\mathrm{Bi} \mathrm{Bi}$ mechanism, the dissociation constants of the products can be calculated from the apparent $K_{1}$ and the concentration of the second substrate; these are $K_{\mathrm{i}, \text { acetylglutamate }} 0.28 \mathrm{mM}$ and $K_{\mathrm{i}, \mathrm{CoA}} 5.6 \mathrm{mM}$.

In the absence of arginine the apparent $K_{\mathrm{m}}$ for glutamate (acetyl-CoA $0.7 \mathrm{~mm}$ ) is $8.7 \mathrm{~mm}$, i.e. in the concentration range found in rat liver mitochondria (3-15 mM; Siess et al., 1977), whereas for acetylCoA (glutamate 3-15 mM) the apparent $K_{\mathrm{m}}$ (4.5$4.6 \mathrm{~mm}$ ) is higher than the intramitochondrial acetyl-CoA concentration $(0.6-0.8 \mathrm{~mm})$. Provided that at physiological $\mathrm{pH}$ the rate constants are not grossly altered, the initial velocity of amino acid acetyltransferase will thus be markedly affected by small changes in substrate concentrations. In addition, the low product-inhibition constant of $N$ acetylglutamate is of interest. The degradation of $\mathrm{N}$-acetylglutamate is negligible in mitochondria, whereas an acylase activity is present in the cytosol (Reglero et al., 1977). Thus Meijer \& Van Woerkom (1979) have postulated that transport of $N$-acetylglutamate across the mitochondrial membrane is needed for preventing its accumulation in the mitochondria.

The dissociation constant of the amino acid acetyltransferase $-N$ - acetylglutamate complex $(0.28 \mathrm{~mm})$ is of the order of magnitude of the intramitochondrial-matrix concentration of $\mathrm{N}$ acetylglutamate found in rats $(0.33 \mathrm{~mm}$ or higher; Cheung \& Raijman, 1980). With $0.33 \mathrm{~mm}-\mathrm{N}$-acetylglutamate and $0.7 \mathrm{~mm}$-acetyl-CoA the initial velocity would thus be decreased by $55 \%$ with $3 \mathrm{~mm}$ glutamate, or by $28 \%$ with $15 \mathrm{~mm}$-glutamate, as compared with the activity without $\mathrm{N}$-acetylglu- 
tamate binding to the enzyme, if the data in vitro could be applied to the situation in vivo. It should, however, be recognized that our measurements were done at $\mathrm{pH} 8.7$ in an artificial buffer and that any $\mathrm{N}$-acetylglutamate produced will also bind to the mitochondrial carbamoyl phosphate synthetase ( $K_{\text {acetylglutamate }} 0.1 \mathrm{mM}$ ), which is present at much higher concentration (approx. 0.4 mM; Cheung \& Raijman, 1980) than amino acid acetyltransferase $(0.1 \mu \mathrm{M})$ as calculated from our results of the purification. More data on the reverse reaction and kinetic studies in the presence of arginine are needed to assess the respective roles of synthesis and transport of $\mathrm{N}$-acetylglutamate out of the mitochondrion in order to understand better the regulation of the early steps of urea synthesis.

This project is supported by the Swiss National Science Foundation grant no. 3.323.077.

\section{References}

Bachmann, C., Krähenbühl, S., Colombo, J.-P., Schubiger, G., Jaggi, K. H. \& Tönz, O. (1981) N. Engl. J. Med. 304, 543
Berüter, J., Colombo, J.-P. \& Bachmann, C. (1978) Biochem.J. 175, 449-454

Cheung, C. W. \& Raijman, L. (1980) J. Biol. Chem. 255, 5051-5057

Colombo, J.-P., Krähenbühl, S. \& Bachmann, C. (1982) J. Clin. Chem. Clin. Biochem. in the press

Dalziel, K. (1957) Acta Chem. Scand. 11, 1706-1723

Hogeboom, G. H. (1955) Methods Enzymol. 1, 16-19

Laurent, T. A. \& Killander, J. (1964) J. Chromatogr. 40, 453-457

Lowry, O. H., Rosebrough, N. J., Farr, A. L. \& Randall, R. J. (1951) J. Biol. Chem. 193, 265-275

Meijer, A. J. \& Van Woerkom, G. M. (1979) Dev. Bioenerg. Biomembr. 3, 365-369

Myers, D. K. \& Slater, E. C. (1957) Biochem. J. 67, 558-572

Reglero, A., Rivas, J., Mendelson, J., Wallace, R. \& Grisolia, S. (1977) FEBS Lett. 81, 13-17

Rudolph, F. B. \& Fromm, H. J. (1979) Methods Enzymol. 63, 138-159

Shigesada, K. \& Tatibana, M. (1971a) Biochem. Biophys. Res. Commun. 44, 117-124

Shigesada, K. \& Tatibana, M. (1971b) J. Biol. Chem. 246, 5588-5595

Siess, E. A., Brocks, D. G., Lattke, H. H. \& Wieland, O. H. (1977) Biochem. J. 166, 225-235

Ushiyama, C., Mori, M. \& Tatibana, M. (1981) J. Biochem. (Tokyo) 89, 1777-1786

Wilkinson, G. N. (1961) Biochem. J. 80, 324-332 